\title{
PENINGKATAN HASIL BELAJAR BIOLOGI MELALUI PENERAPAN INTEGRASI GROUP INVESTIGATION DANINKUIRI TERBIMBING BERBASIS LESSON STUDY
}

\author{
Muhammad Mifta Fausan ${ }^{1}$, Indah Panca Pujiastuti ${ }^{2}$ \\ ${ }^{\mathbf{1 , 2}}$ Prodi Pendidikan Biologi, Fakultas MIPA, Universitas Sulawesi Barat, Jalan Prof. Dr. Baharuddin Lopa Majene \\ e-mail: fausan@unsulbar.ac.id
}

\section{ABSTRAK}

Pendidikan di abad XXI dihadapkan pada era pengetahuan yang membutuhkan berbagai modal intelektual yang perlu dimiliki oleh siswa.Sebuah realita berdasarkan hasil observasi yang dilakukan peneliti pada kelas X-IPA 1 MAN 3 Malang memperlihatkan bahwa hasil belajar siswa masih tergolong rendah. Indikator rendahnya hasil belajar biologi tampak dari nilai rata-rata ulangan harian, yaitu lebih dari $70 \%$ siswa yang mendapat nilai di bawah Kriteria Belajar Minimum Sekolah yaitu 75. Salah satu cara yang dapat meningkatkan hasil belajar biologi siswa adalah dengan menerapkan integrasi model pembelajaran group investigationdan inkuiri terbimbing berbasis lesson study.Penelitian ini bertujuan untuk meningkatkan hasil belajar kognitif, afektif, dan psikomotor biologi siswa kelas X-IPA 1 MAN 3 Malang. Penelitian ini merupakan Penelitian Tindakan Kelas berbasis Lesson Studyyang dilaksanakan dalam 2 siklus,serta melalui tahapanplan, do, dan see. Hasil belajar yang telah dicapai siswa pada siklus I ke siklus II adalah 80,4meningkat menjadi 90 (hasil belajar kognitif); 93 meningkat menjadi 98 (hasil belajar afektif); dan 98 meningkat menjadi 99 (hasil belajar psikomotor).Berdasarkan hasil penelitian dapat disimpulkan bahwa terjadi peningkatan hasil belajar biologi siswa dari siklus I ke siklus II.

Kata kunci: Group Investigation, hasil belajar biologi, inkuiri terbimbing, Lesson Study

\section{ABSTRACT}

Education in the XXI century faced with an era of knowledge that required various intellectual basic that students needed to possess. A reality based on observations made by researcher in the class X-IPA 1 MAN 3 Malang shows that student learning outcomes are still relatively low. The low indicator of biological learning outcomes appears from the average daily test score of more than $70 \%$ of students who scored below the minimum criteria of 75 . One way that can improve students' biology learning outcomes is by applying the integration of the Group Investigation learning model and guided inquiry based lesson study. This study aims to improve the learning outcomes of cognitive, affective, and psychomotor biology of students of class X-IPA 1 MAN 3 Malang. This study is a Classroom Action Research based Lesson Study which is implemented in 2 cycles, and through stages plan, do, and see. Learning outcomes that have been achieved by students in cycle I to cycle II is 80.4 increased to 90 (cognitive learning outcomes); 93 increased to 98 (affective learning result); and 98 increased to 99 (psychomotor learning outcomes). Based on the results of the study can be concluded that there is an increase in student biology learning outcomes from cycle I to cycle II.

Keywords: Group Investigation, biology learning outcomes, guided inquiry, Lesson Study

\section{PENDAHULUAN}

Pendidikan di abad XXI, dihadapkan pada era pengetahuan yang membutuhkan berbagai modal intelektual yang perlu dimiliki oleh siswa.Sebuah realita berdasarkan hasil observasi yang dilakukan peneliti pada kelas X-IPA 1 MA Negeri 3 Malang memperlihatkan bahwa hasil belajar siswa masih tergolong rendah. Indikator rendahnya hasil belajar biologi tampak dari nilai rata-rata ulangan harian, yaitu lebih dari $70 \%$ siswa yang mendapat nilai di bawah Kriteria Belajar Minimum Sekolah yaitu 75 . Salah satu cara yang dapat meningkatkan hasil belajar biologi siswa adalah dengan menerapkan integrasi model pembelajaran Group
Investigation (GI) dan inkuiri terbimbing berbasis Lesson Study(LS).GI merupakan salah satu model pembelajaran kooperatif.Fausan dan Pujiastuti (2017) menyatakan bahwa hasil belajar siswa dari siklus 1 ke siklus 2 dapat ditingkatkan melalui penerapan pembelajaran yang bersifat kooperatif.

Group investigation adalah strategi pembelajaran yang dirancang agar siswa bekerja dalamkelompok untuk memecahkan masalah dan mengembangkan keterampilan meneliti. Tiap kelompok diberi tanggung jawab untuk memilih topik yang diminati, membagi tugas-tugas menjadi sub-sub topik, dan menentukan caramelaksanakan penelitian sub-sub topik tersebut. Mereka juga 
mengintegrasikan materi sub-sub topik untuk menyusun laporan kelompok. Laporan hasil kerja kelompok dilaporkan ke semua anggota kelas (diskusi kelas).Tes diadakan setelah diskusi kelas, dan hasilnya berupa rata-rata skor tiap kelompok yang diumumkan kepada seluruh siswa (Susanto, 2006). Nurhadi (2002) menjelaskan bahwa model GI melibatkan siswa sejak perencanaan, baik dalam menentukan topik maupun cara untuk mempelajarinya melalui investigasi.

Pavelich dan Abraham (1977) dalam Taufiq (2012) menyatakan bahwa pembelajaran dengan metode inkuiri terbimbing memberikan kebebasan siswa untuk memilih atau mengemukakan masalah, merencanakan eksperimen, menganalisis data, dan menyimpulkan. Pembelajaran dengan inkuiri terbimbing, pemilihan masalah dan rencana eksperimen dilakukan oleh guru, sedangkan analisis dan membuat kesimpulan dilakukan oleh siswa.

Integrasi model pembelajaran GI dan inkuiri terbimbing adalah metode pembelajaran dengan sintaks sebagai berikut. Tahap I: Mengidentifikasi topik dan mengorganisasikan siswa ke dalam kelompok (integrasi GI dan inkuiri terbimbing). Tahap II: Diskusi masalah (inkuiri terbimbing). Tahap III: Merencanakan tugas-tugas belajar (integrasi GI dan inkuiri terbimbing). Tahap IV: Melaksanakan investigasi (integrasi GI dan inkuiri terbimbing). Tahap V: Menyiapkan laporan akhir (GI). Tahap VI: Mempresentasikan laporan akhir (GI). Tahap VII: Kesimpulan (GI). Tahap VIII: Evaluasi (GI). Tahap IX: Ekstensi/ pengulangan (inkuiri terbimbing). Tahap $\mathrm{X}$ : Penghargaan kelompok (GI).

Menurut Susilo (2012), lesson studymerupakan suatu bentuk utama peningkatan kualitas pembelajaran dan pengembangan keprofesionalan guru yang dipilih oleh guru-guru di Jepang. Dalam melakukan lesson study, guru secara kolaboratif dalam: (1) mempelajari kurikulum, dan merumuskan tujuan pengembangansiswanya (pengembangan kecakapan hidupnya), (2) merancang pembelajaran untuk mencapai tujuan, (3) melaksanakan dan mengamati suatu research lesson (pembelajaran yang dikaji), dan (4) melakukan refleksi untuk mendiskusikan pembelajaran yang dikaji, menyempurnakannya dan merencanakan pembelajaran berikutnya. Tahap-tahap pelaksanaan lesson study adalah perencanaan (plan), pelaksanaan (do), dan refleksi (see).

Penelitian ini bertujuan untuk meningkatkan hasil belajar kognitif, afektif, dan psikomotor biologi siswa kelas X-IPA 1 MAN 3 Malang. Penelitian ini merupakan Penelitian Tindakan Kelas (PTK) yang berbasis lesson studydan dilaksanakan dalam 2 siklus,serta melalui tahapanplan, do, dan see.Beberapa penelitian yang berkaitan dengan GI diantaranya adalah penelitian yang telah dilakukan oleh Nurlitasari, pada tahun 2007 dengan judul “Penerapan Pembelajaran Kooperatif Model Group Investigation (GI) untuk Meningkatkan Kerja IImiah dan Hasil Belajar Siswa dalamPembelajaran Biologi Kelas X.1 SMA LaboratoriumUniversitas Negeri Malang". Hasil penelitian Nurlitasari menunjukkan peningkatan hasil belajar siswa dari siklus I ke siklus II sebesar $2,1 \%$.

Penelitian yang dilakukan oleh Taufiq (2012) dengan judul "Penggunaan Metode Inkuiri berbasis lesson studyuntuk Meningkatkan Proses dan Hasil Belajar Biologi pada Siswa Kelas X SMA Negeri Talun Kabupaten Blitar" juga menunjukkan adanya peningkatan hasil belajar siswa. Hasil belajar dari siklus I $(66,6 \%)$ ke siklus II $(83,3 \%)$ terjadi peningkatan sebesar $16,7 \%$.

\section{METODE PENELITIAN}

Penelitian ini menggunakan pendekatan kualitatif karena data yang diperoleh berupa katakata atau kalimat sedangkan data yang berupa angka akan diolah dan dianalisis menggunakan kata-kata. Jenis penelitiannya menggunakan Penelitian Tindakan Kelas (PTK), yang dilakukan dalam rangka meningkatkan hasil praktik pembelajaran di sekolah.PTK dilakukan dalam siklus yang terdiri dari 4 tahap, yaitu tahapan perencanaan tindakan (planning), pelaksanaan tindakan (action), observasi (observation), dan refleksi (reflection).Apabila siklus pertama belum tercapai keberhasilan, maka berlanjut pada 2 siklus.Dalam setiap siklus terdapat kegiatan lesson studyyang memiliki 3 tahapan, yaitu plan, do, dan see. Peneliti dibantu oleh 3 orang rekan peneliti dan guru bidang studi Biologi untuk bertindak sebagai observer.

Arikunto (2013) menyatakan bahwa instrumen penelitian adalah alat atau fasilitas yang 
digunakan oleh peneliti dalam mengumpulkan data agar pekerjaannya lebih mudah dan hasilnya lebih baik, dalam arti lebih cermat, lengkap, dan sistematis, sehingga mudah diolah.Instrumen penelitian yang digunakan dalampenelitian ini adalah untuk mengukur peningkatan hasil belajar siswa.

Analisis data dalam penelitian ini dilakukan oleh peneliti.Teknik analisis data yang digunakan adalah analisis data kualitatif-kuantitatif.Data yang dianalisis dikumpulkan dengan menggunakan lembar soal ulangan harian untuk hasil belajar kognitif dan lembar observasi hasil belajar afektif dan psikomotor.Peningkatan hasil belajar yang dicapai oleh siswa dihitung berdasarkan rumus sebagai berikut.

a. Hasil belajar kognitif

1) Secara perorangan (individual), dianggap telah tuntas belajar apabila skor mencapai > 75.

2) Secara klasikal, dianggap tuntas belajar apabila mencapai $85 \%$ dari jumlah siswa yang mencapai skor $>75$.

Untuk mencari ketuntasan belajar klasikal digunakan rumus sebagai berikut.
Ketuntasan belajar klasikal =

$\frac{\Sigma \text { siswa yang tuntas belajar }}{\Sigma \text { sehuru } h \text { siswa }} \times 100 \%$

$\Sigma$ seluru $h$ siswa

b. Hasil belajar afektif dan psikomotor dihitung melalui rumus sebagai berikut.

$$
\mathrm{P}=\frac{\sum \text { skor }}{N} \times 100 \%
$$

Keterangan:

$\mathrm{P} \quad=$ persentase skor afektif/ psikomotor

$\Sigma$ skor= total skor afektif/ psikomotor

$\mathrm{N} \quad$ = jumlah skor ideal/maksimal

Kriteria persentase keberhasilan tindakan yaitu: jika skornya 86-100 (sangat baik), 76-85\% (baik), 60-75 (cukup), 55-59(kurang), $\leq 54$ (sangat kurang).

\section{HASIL PENELITIAN}

Data yang diperoleh oleh para observer selama mengamati guru dalam penelitian penerapan integrasi model pembelajaran group investigationdan inkuiri terbimbing berbasis lesson studyini meliputi tahapan plan, do, dan see. Perbandingan hasil keterlaksanaan lesson studypada siklus I dengan siklus II ditunjukkan pada Tabel 1.

Tabel 1Perbandingan Hasil Keterlaksanaan Lesson Study

\begin{tabular}{llccccc}
\hline No. & $\begin{array}{c}\text { Indikator } \\
\text { Lesson } \\
\text { Study }\end{array}$ & $\begin{array}{c}\text { Rerata } \\
\text { indikator }\end{array}$ & $\begin{array}{c}\text { Kategori } \\
\text { keberhasilan } \\
\text { tindakan }\end{array}$ & $\begin{array}{c}\text { Rerata } \\
\text { indikator }\end{array}$ & $\begin{array}{c}\text { Kategori keberhasilan } \\
\text { tindakan }\end{array}$ & Selisih rerata \\
\hline 1. & Plan & 75 & Cukup & 98 & Sangat baik & 23 \\
\hline 2. & Do & 90 & Sangat baik & 93 & Sangat baik & 3 \\
\hline 3. & See & 88 & Sangat baik & 100 & Sangat baik & 12 \\
\hline & Rerata & 84 & Baik & 97 & Sangat baik & 13 \\
\hline
\end{tabular}

Tabel 1 menunjukkan bahwa rerata keterlaksanaan lesson study mengalami peningkatan 13 poin dari siklus I (84) ke siklus II (97) pada setiap tahapan plan, do, dan see. Data hasil belajar kognitif, afektif, dan psikomotor siswa yang diperoleh selama pelaksanaan tindakan dan observasi siklus I dan siklus II kemudian dianalisis dan berturut-turut dapat dilihat pada Tabel 2, Tabel 3, Tabel 4.

Tabel 2.Perbandingan Hasil Belajar KognitifSiswa

\begin{tabular}{ccccc}
\hline \multicolumn{2}{c}{ Siklus I } & \multicolumn{2}{c}{ Siklus II } & Selisih rerata kelas \\
\cline { 1 - 4 } $\begin{array}{c}\text { Persentase } \\
\text { ketuntasan }\end{array}$ & Rerata kelas & $\begin{array}{l}\text { Persentase } \\
\text { ketuntasan }\end{array}$ & Rerata kelas & \\
\hline $74 \%$ & 80,4 & $100 \%$ & 90 & 9,5 \\
\hline
\end{tabular}


Tabel 3. Perbandingan Hasil Belajar Afektif Siswa

\begin{tabular}{|c|c|c|c|c|c|c|}
\hline \multirow[b]{2}{*}{ No. } & \multirow[b]{2}{*}{$\begin{array}{l}\text { Indikator hasil } \\
\text { belajar afektif }\end{array}$} & \multicolumn{2}{|c|}{ Siklus I } & \multicolumn{2}{|c|}{ Siklus II } & \multirow[b]{2}{*}{ Selisih rerata } \\
\hline & & $\begin{array}{c}\text { Rerata } \\
\text { indikator }\end{array}$ & $\begin{array}{c}\text { Kategori } \\
\text { keberhasilan } \\
\text { tindakan }\end{array}$ & $\begin{array}{c}\text { Rerata } \\
\text { indikator }\end{array}$ & $\begin{array}{c}\text { Kategori } \\
\text { keberhasilan } \\
\text { tindakan }\end{array}$ & \\
\hline 1. & Menerima & 93 & Sangat baik & 99 & Sangat baik & 6 \\
\hline 2. & Menjalankan & 91 & Sangat baik & 99 & Sangat baik & 8 \\
\hline 3. & Menghargai & 95 & Sangat baik & 96 & Sangat baik & 1 \\
\hline 4. & Menghayati & 91 & Sangat baik & 96 & Sangat baik & 5 \\
\hline & Mengamalkan & 95 & Sangat baik & 100 & Sangat baik & 5 \\
\hline \multicolumn{2}{|c|}{$\begin{array}{c}\text { Rerata hasil belajar } \\
\text { afektif }\end{array}$} & 93 & Sangat baik & 98 & Sangat baik & 6 \\
\hline & Ketuntasan & $96 \%$ & Sangat baik & $100 \%$ & Sangat baik & $4 \%$ \\
\hline
\end{tabular}

Tabel 4. Perbandingan Hasil Belajar Psikomotor Siswa

\begin{tabular}{|c|c|c|c|c|c|c|}
\hline \multirow[b]{2}{*}{ No. } & \multirow[b]{2}{*}{$\begin{array}{l}\text { Indikator hasil } \\
\text { belajar psikomotor }\end{array}$} & \multicolumn{2}{|c|}{ Siklus I } & \multicolumn{2}{|c|}{ Siklus II } & \multirow[b]{2}{*}{$\begin{array}{l}\text { Selisih } \\
\text { rerata }\end{array}$} \\
\hline & & $\begin{array}{c}\text { Rerata } \\
\text { indikator }\end{array}$ & $\begin{array}{c}\text { Kategori } \\
\text { keberhasilan } \\
\text { tindakan }\end{array}$ & $\begin{array}{c}\text { Rerata } \\
\text { indikator }\end{array}$ & $\begin{array}{c}\text { Kategori } \\
\text { keberhasilan } \\
\text { tindakan }\end{array}$ & \\
\hline 1. & Kesiapan & 95 & Sangat baik & 98 & Sangat baik & 3 \\
\hline 2. & Mengamati & 95 & Sangat baik & 98 & Sangat baik & 3 \\
\hline 3. & Menanya & 100 & Sangat baik & 100 & Sangat baik & 0 \\
\hline 4. & Mencoba & 95 & Sangat baik & 100 & Sangat baik & 5 \\
\hline 5. & Menalar & 96 & Sangat baik & 100 & Sangat baik & 4 \\
\hline 6. & Menyaji & 100 & Sangat baik & 100 & Sangat baik & 0 \\
\hline 7. & Bertanggung jawab & 100 & Sangat baik & 100 & Sangat baik & 0 \\
\hline 8. & Mencipta & 100 & Sangat baik & 100 & Sangat baik & 0 \\
\hline \multicolumn{2}{|c|}{$\begin{array}{l}\text { Rerata hasil belajar } \\
\text { psikomotor }\end{array}$} & 98 & Sangat baik & 99 & Sangat baik & 1 \\
\hline & Ketuntasan & $100 \%$ & Sangat baik & $100 \%$ & Sangat baik & $0 \%$ \\
\hline
\end{tabular}

Tabel 2 menunjukkan bahwa rerata hasil belajar kognitif siswa mengalami peningkatan 9,5 poin dari siklus I $(80,4)$ dengan ketuntasan $74 \%$ ke siklus II (90) dengan ketuntasan 100\%. Tabel 3 menunjukkan bahwa rerata hasil belajar afektif siswa mengalami peningkatan 6 poin dari siklus I (93) dengan ketuntasan 96\% ke siklus II (98) dengan ketuntasan 100\%.Tabel 4 menunjukkan bahwa rerata hasil belajar psikomotor siswa mengalami peningkatan 1 poin dari siklus I (98) dengan ketuntasan $100 \%$ ke siklus II (99) dengan ketuntasan $100 \%$.

Keterlaksanaan lesson study disetiap siklus dalam penelitian ini semakin baik dan sangat baik. Hal ini terjadi karena peneliti dan observer secara kolaboratif dan berkesinambungan melakukan upaya untuk memperbaiki proses pembelajaran yang dilakukan dalam perencanaan, pelaksanaan, pengamatan, dan pelaporan hasil observasi. Hasi penelitian Ono (2010) dan Asyari (2016) memaparkan bahwa dalam lesson study peneliti harus berkolaborasi dalam upaya memperbaiki proses pembelajaran, karena pada prinsipnya lesson study merupakan sebuah alternatif bentuk pengembangan profesionalme guru. Selanjutnya Asyari (2015) menambahkan bahwa melalui lesson study, guru belajar banyak dari fakta yang ditemukan di kelas.

Belajar merupakan tindakan dan perilaku siswa yang kompleks. Siswa merupakan penentu terjadi atau tidaknya proses belajar. Dimyati dan Mudjiono (2007) menyatakan bahwa hasil belajar merupakan hasil dari sutau interaksi belajar mengajar yang ditandai dengan perubahan perilaku, pola pikir dan mental. Proses pembelajaran sepenuhnya diarahkan pada pengembangan ketiga ranah tersebut secara utuh/holistik, artinya pengembangan ranah yang satu tidak bisa dipisahkan dengan ranah lainnya. Dengan demikian proses pembelajaran secara utuh 
melahirkan kualitas yang mencerminkan keutuhan penguasaan sikap, pengetahuan, dan keterampilan. Penelitian ini menggunakan pengukuran hasil belajar ranah kognitif, afektif, dan psikomotor.

Hasil belajar kognitif diukur melalui pelaksanaan tes tertulis di setiap akhir siklus dengan jumlah soal sebanyak 10 butir pilihan ganda dan 5 butir soal uraian.Berdasarkan hasil analisis data diketahui bahwa hasil belajar dari siklus I ke siklus II mengalami peningkatan. Hal ini dapat dilihat pada Tabel 2, dimana persentase ketuntasan hasil belajar siswa pada siklus I adalah $74 \%$, sedangkan pada siklus II meningkat menjadi $100 \%$, yang artinya terjadi peningkatan $26 \%$.

Peningkatan hasil belajar kognitif siswa $X-$ IPA 1disebabkan oleh beberapa hal, di antaranya: 1) Pembentukan kelompok yang heterogen, sehingga siswa yang lebih pandai dapat menjadi tutor bagi siswa yang kurang pandai sehingga dapat menciptakan interaksi yang positif. Hal ini sejalan dengan hasil penelitian Dewi (2012) yang menyatakan bahwa dengan pembelajaran kelompok, maka siswa dapat bertukar pendapat antar teman sebaya, memecahkan masalah bersama sehingga dapat meningkatkan minat siswa dalam belajar; 2) model pembelajaran kooperatif tipe Glyang dilaksanakan sesuai dengan prosedur, sehingga dapat Menciptakan suasana belajar yang menyenangkan.Suasana belajar ini membuat siswa termotivasi untuk berperan aktif dalam proses pembelajaran. Kondisi ini sejalan dengan Sumiati dan Arsa (2008) yang menyatakan bahwa "motivasi siswa akan terlihat apabila terdapat suasana yang nyaman dan menyenangkan dalam proses pembelajaran serta antara guru dengan siswa terjadi komunikasi yang akrab dan menyenangkan"; 3) Integrasi model pembelajaran GI dan inkuiri terbimbing menuntut siswa untuk mencari pengetahuannya sendiri, sehingga pengetahuan yang telah didapat akan lebih mudah diingat. Peningkatan hasil belajar pada penelitian ini sejalan dengan penelitian para peneliti sebelumnya, diantaranya penelitian yang dilakukan oleh Nurlitasari (2007), yang memaparkan bahwa pada penerapan model pembelajaran group investigation dapat meningkatkan hasil belajar siswa dari siklus I ke siklus II sebesar 2,1\%. Selanjutnya Taufiq (2012) dengan judul
"Penggunaan Metode Inkuiri berbasis lesson studyuntuk meningkatkan Proses dan Hasil Belajar Biologi pada Siswa Kelas X SMA Negeri Talun Kabupaten Blitar" juga menunjukkan adanya peningkatan hasil belajar kognitif siswa. Hasil belajar dari siklus I $(66,6 \%)$ ke siklus II $(83,3 \%)$ terjadi peningkatan sebesar $16,7 \%$.

Hasil belajar afektif adalah sikap siswa dalam kegiatan pembelajaran. Hasil belajar afektif diperoleh berdasarkan observasi yang dilakukan oleh para observer pada saat proses pembelajaran yang berlangsung dengan menggunakan lembar observasi. Berdasarkan hasil analisis yang telah dilakukan, semua aspek yang diukur (menerima, menjalankan, menghargai, menghayati, dan mengamalkan)mempunyai nilai yang sangat baik.Rerata kelas pada siklus I adalah 93, dengan persentase ketuntasan 96\%.Rerata kelas pada siklus II adalah 98, dengan persentase ketuntasan 100\%.Aspek yang diukur dalam penelitian ini sesuai dengan yang dinyatakan oleh Rusman (2017) yaitu aspek afektif diperoleh melalui menerima, menjalankan, menghargai, menghayati, dan mengamalkan. Hasil penelitian inijuga sejalan dengan yang diungkapkan oleh Susilo (2012) bahwa lesson study menargetkan pencapaian berbagai kualitas siswa yang mempengaruhi kegiatan belajar dengan kecerdasan berpikir dan bersikap. Peningkatan hasil belajar afektif terhadap proses pembelajaran yang dilaksanakan, menunjukkan bahwa pembelajaran dengan menggunakan integrasi model pembelajaran GI dan inkuiri terbimbing dapat melatih siswa untuk bersikap yang lebih baik.

$\begin{array}{lllr}\text { Hasil belajar psikomotor berupa } & \text { melakukan } \\ \text { keterampilan fisik dalam } & \text { mikomotor } \\ \text { eksperimen/pengamatan. Ranah } & \text { psikomo }\end{array}$
diperoleh dari kegiatan observasi pada saat siswa melakukan investigasi (sintaks integrasi GI dan inkuiri terbimbing). Berdasarkan hasil analisis data, dapat diketahui bahwa hasil belajar psikomotor (kesiapan, mengamati, menanya, mencoba, menalar, menyaji, bertanggung jawab, dan mencipta) meningkat dari siklus I ke siklus II setelah pelaksanaan pembelajaran dengan menggunakan integrasi model pembelajaran GI dan inkuiri terbimbing berbais lesson study. Rerata kelas pada siklus I adalah 98, dengan persentase ketuntasan $100 \%$. Rerata kelas pada siklus II adalah 
99, dengan persentase ketuntasan 100\%. Hasil penelitian ini sesuai dengan yang diungkapkan oleh Zubaidah (2016) yaitu kehidupan di abad ke21 menuntut berbagai keterampilan yang harus dikuasai seseorang, sehingga diharapkan pendidikan dapat mempersiapkan siswa untuk menguasai berbagai keterampilan tersebut agar menjadi pribadi yang sukses dalam hidup.

\section{KESIMPULAN}

Kesimpulan dalam penelitian ini adalah terjadi peningkatan hasil belajar kognitif, afektif, dan psikomotor biologi siswa kelas X-IPA 1 MAN 3 Malang melalui integrasi model pembelajaran group investigationdan inkuiri terbimbing berbasis lesson study.

\section{DAFTAR PUSTAKA}

Arikunto, Suharsimi. 2013. Dasar-Dasar Evaluasi Pendidikan. Jakarta: Bumi Aksara

Asyari, Marhamah.,Muhdhar, Mimien Henie Irawati., Susilo, Herawati dan Ibrohim. 2016. Improving Critical Thinking Skills Through the Integration of Problem Based Learning and Group Investigation. International Journal for Lesson and Learning Studies. 5 (1): 36-44.

Dewi, Ratih Puspita., Iswari, Retno Sri dan Susanti. 2012. Penerapan Model Group Investigation Terhadap Hasil Belajar Materi Bahan Kimia di SMP. Unnes Journal of Biology Education. Vol. 1(3): 279-286.

Dimyati dan Mudjiono. 2009. Belajar dan pembelajaran. Jakarta: PT Rineka Cipta.

Fausan, Muhammad Mifta dan Pujiastuti, Indah Panca. 2017. The Effect of CTL Approach Based on NHT Learning Model to Student's Motivation, Science Achievement, and Retention. JPBI (Jurnal Pendidikan Biologi Indonesia). Vol. 3 (2): 51-60.

Nurhadi. 2002. Pendekatan Kontekstual (Contextual Teaching and Learning/CTL). Jakarta: Departemen Pendidikan Nasional.

Nurlitasari, Dewi. 2007. Penerapan Pembelajaran Kooperatif Model Group Investigation (GI) untuk Meningkatkan Kerja IImiah dan Hasil Belajar Siswa dalam Pembelajaran Biologi Kelas X.1 SMA Laboratorium Universitas Negeri Malang. Skripsi.Tidak diterbitkan. Malang: Universitas Negeri Malang.

Ono, Yumiko. dan Ferreira, Johanna. 2010. A Case Study of Continuing Teacher Professional Development through Lesson Study in South Africa. South African Journal of Education. Vol. 30(1): 59-74

Rusman. 2017. Belajan dan Pembelajaran Berorientasi Standar Proses Pendidikan. Jakarta: Kencana.

Sumiati dan Arsa. 2008. Metode Pembelajaran. Bandung: CV Wacana Prima.

Susanto, Pudyo. 2006. Buku Petunjuk Teknis Praktik Pengalaman Lapangan Bidang Studi Pendidikan Biologi. Malang: UPT PPL UM.

Susilo.Herawati. 2012. Pemanfaatan Kemampuan Melaksanakan Penelitian Tindakan Kelas/Penelitian Tindakan Sekolah untuk Menunjang Proses Pendidikan dan Pembelajaran di Sekolah. QUANTUM, Jurnal Inovasi Pendidikan Sains. Vol. 3(2): 81-102.

Taufiq. 2012. Penggunaan Metode Inkuiri Berbasis Lesson Study (LS) untuk Meningkatkan Proses dan Hasil Belajar Biologi pada Siswa Kelas X SMA Negeri Talun Kabupaten Blitar. Tesis. Tidak Diterbitkan. PPs UM.

Zubaidah, Siti. 2016. Keterampilan Abad ke-21: Keterampilan yang Diajarkan Melalui Pembelajaran. Seminar Nasional Pendidikan dengan tema "Isu-isu Strategis Pembelajaran MIPA Abad 21.STKIP Persada Khatulistiwa Sintang Kalimantan Barat. 